\title{
BMJ Open Study protocol for a matter of heart: a qualitative study of patient factors driving overuse of cardiac catheterisation
}

\author{
Anna Herwig, Birgitta Weltermann
}

To cite: Herwig A, Weltermann B. Study protocol for a matter of heart: a qualitative study of patient factors driving overuse of cardiac catheterisation. BMJ Open 2017;7:e017629. doi:10.1136/ bmjopen-2017-017629

- Prepublication history for this paper is available online. To view these files please visit the journal online (http://dx.doi. org/10.1136/bmjopen-2017017629 ).

Received 3 May 2017

Revised 21 July 2017

Accepted 27 July 2017

CrossMark

Institute for General Medicine, University Hospital Essen, University of Duisburg-Essen, Essen, Germany

Correspondence to

Anna Herwig;

anna.herwig@uk-essen.de

\section{ABSTRACT}

Introduction Overuse of cardiac catheterisation (CC) for stable coronary artery disease (CAD) is documented in Germany and other regions, although percutaneous coronary interventions do not provide a benefit over medical therapy for stable patients. Various studies investigated health system, physician and patient factors driving non-adherence to guidelines which recommend a stepwise approach with invasive procedures only in case of signs of ischaemia in non-invasive testing. In a largerscale project, we aim to better understand the patients' perspective in order to develop an intervention that enhances patient's acceptance of this stepwise diagnostic approach for stable CAD. As a first step, this qualitative study aims to identify patient factors that prevent and promote the described overuse.

Methods and analysis The exploratory qualitative interview study will include about 20 patients with stable $\mathrm{CAD}$ and a history of acute coronary syndrome from two German teaching practices. Narrative, structured interviews designed to last 30 to 90 min will be conducted. The interviews will be analysed using qualitative content analysis by Mayring. The analysis will address the following questions: (1) What are reasons for stable patients to undergo CC? (2) How do patients deal with their heart disease (secondary prevention)? (3) Which processes do patients describe regarding decision-making for noninvasive and invasive coronary procedures? (4) What information needs exist on behalf of patients to better understand the stepwise diagnostic approach outlined in guidelines and thereby avoid low-appropriate CCs? Based on these data, empirical typification will be conducted.

Ethics and dissemination Ethical approval for the study was obtained. All participants will provide written informed consent. Data will be pseudonymised for analysis. The findings will contribute to the development of an appropriate intervention. Results will be disseminated by conference presentations and journal publications.

\section{INTRODUCTION}

Overuse of cardiac catheterisation (CG) with and without interventions for asymptomatic patients with stable coronary artery disease (CAD) is documented for Germany, the USA and Canada. ${ }^{12}$ It is estimated that $4 \%-18 \%$ of

\section{Strengths and limitations of this study}

- Limited research focused on the patient's perspective; our study will bring a new perspective on the overuse of cardiac catheterisation.

- Large number of interviews ensure a wide range of factors.

- New insights on how to communicate with patients are expected.

- Preselection by physicians may cause a bias.

- The study will be conducted in one geographical region; it may not be representative for other health systems or areas

coronary angiography procedures in the USA and Canada are inappropriate according to guidelines. ${ }^{2}$ Although conflicting data of the scope of overuse in Germany are reported, country comparisons show markedly higher rates compared with nations such as Sweden and the Netherlands, without any difference in cardiovascular mortality. ${ }^{34}$

Evidence shows that percutaneous coronary interventions (PCI) do not provide a benefit in quality of life compared with medical therapy in stable CAD. ${ }^{56}$ Therefore, guidelines recommend a stepwise approach with invasive testing for patients with signs of ischaemia in non-invasive testing. ${ }^{27-10} \mathrm{~A} 2015$ Swiss study from Chmiel $e t a l^{11}$ revealed that $37.5 \% \quad(n=1018)$ of 2714 stable patients had not received non-invasive diagnostics prior to coronary angiography. In a retrospective study of 147 individual patient careers spanning back up to 28 years, we showed that patients with more than 10 CCs in a lifetime had a higher rate of procedures classified as 'low appropriateness' (72\%) compared with those with fewer procedures $(20 \%$ in $1-5$ procedures and $52 \%$ in $6-9$ procedures). ${ }^{12}$

Analysing factors that drive such overuse of CC studies describe three aspects, that is, healthcare system, physician and patient 
factors. Health system factors comprise, for example, the availability of and access to CC laboratories as well as economic incentives within health systems. ${ }^{1314}$ A 1994 study in three UK cardiac centres showed that the use of CC varied significantly, with a higher rate of CC in the two centres with in-house cardiothoracic surgery. The authors assumed that the physicians' philosophy as well as the availability of surgery play a role. ${ }^{15}$ A national cohort study of 158831 elderly patients followed for up to 7 years after a hospital stay for acute myocardial infarction showed marked differences by region of residency regarding the medical management and the intensity of invasive procedures: patients in regions with more CC laboratory capacities were more likely to receive interventional procedures, regardless of their age, clinical indication or risk profile. ${ }^{16}$ Similarly, a 2003 Canadian study examining payment claims for physician services in 47036 inpatients with acute myocardial infarction found that hospitals with on-site catheterisation laboratories, those with university affiliations and those closer to tertiary institutions showed a higher 90-day angiography use. ${ }^{17}$

More recently, studies focused on physician factors driving overuse. A 2007 focus group study asked 20 US cardiologists about their intentions to use PCI for stable CAD. The authors showed that physicians had a firm belief in the benefits of the new technologies, and they feared bad outcomes and/or being sued if they did not use PCI. Some even reported negative experiences like a young patient dying of CAD. Also, physicians argued that it is better to visualise the coronary arteries than to rely on non-invasive results (so-called 'oculostenotic reflex'). Also, they aimed to reduce patients' anxieties and wish to match patients' requests. ${ }^{18}$ In a qualitative study, 40 interactions between US cardiologists and patients with stable angina from the Verilogue Point-of-Practice Database were analysed in detail. In general, cardiologists overstated the benefits of coronary interventions and understated the associated risks and alternatives. ${ }^{19}$

Other studies addressed patient factors that drive an overuse of CC. A questionnaire study from Rothberg et $a l^{20}$ showed a marked discrepancy between US cardiologists' and patients' beliefs about the effects of PCI. While physicians aimed at symptom relief, three quarters of the 153 patients with elective CC believed in a prognostic benefit and were convinced that they would suffer from a myocardial infarction within the next 5 years without PCI; also, $88 \%$ believed that PCI could actually reduce their risk for a myocardial infarction, while a smaller group of 16 patients stated to elect a CC to reduce their anxieties. ${ }^{20}$ According to a US mail survey among 472 patients who had undergone coronary artery stenting, the majority of patients stated that they were not involved in decision-making at all: only $10 \%$ of the patients said that physicians discussed an alternative intervention including coronary artery bypass graft surgery or medication management, and only $16 \%$ of the patients reported that the physician had asked about their personal preference. ${ }^{21}$ Furthermore, the role of patients' emotional factors is supported by a study by Ockene $e t a l^{22}$ in 57 patients in whom normal coronary arteries and no other heart disease were diagnosed by CC. Prior to the diagnostic procedure, $79 \%(n=45)$ were convinced of suffering from heart disease; interestingly, 16 months after CC, $44 \%(n=25)$ were still convinced of an undiagnosed heart disease. In agreement with others, this study concluded that uncertainties and fears play a major role, and that these should be addressed by adequate patient information. However, interventions with proven effectiveness to address the various factors on behalf of patients with stable CC, for example, lack of information, inadequate risk perception and emotional factors, are missing. ${ }^{22}$ Also, it is unclear whether there are different types of patients which may require different information strategies.

To better prevent overuse of CC, we assume that it is important to obtain a more in-depth understanding which factors influence stable patients' decisions for invasive procedures. Therefore, this qualitative study uses a transdisciplinary approach well established in sociology and social sciences. Based on the reasons of stable patients to opt for CC, we will conduct an empirical typification to describe the relationship between a patient's attitude towards medical information and their trust in suggested treatments and decisions for CC with low appropriateness. We assume that patients have different attitudes towards the healthcare environment which result in different decisions and actions even in comparable situations. To show that, we will draw on and integrate findings of a 2007 German study which addressed patients' normative values and behavioural patterns in the healthcare system. Based on about 1500 randomly selected participants from the general population, four types of patients were characterised: (1) the indifferent patient, who has little interest in gathering medical information and little trust in medical treatment, (2) the accepting patient, who has little interest in gathering medical information and high trust in medical treatment, (3) the sceptical patient, who has high interest in gathering medical information and little trust in medical treatment and (4) the cophysician, who has high interest in gathering information and high trust in medical treatment. ${ }^{23}$ We expect that these four different types of patients can also be found among patients with stable CAD, and that these deal differently with their heart disease, describe different processes in decision-making, have different reasons for undergoing a CC and need different information strategies to avoid CCs of low appropriateness.

\section{METHODS AND ANALYSIS}

\section{Study setting and design}

The interviews will be conducted in two German teaching practices which are affiliated with our Institute for General Medicine. Teaching physicians will select patients with a history of acute coronary syndrome (ACS) who underwent at least one or better yet multiple coronary catheterisation procedures with or without intervention. 
The interviews will be conducted by a female researcher who is qualified and experienced in qualitative research methods and interview techniques. Each interview will last about 30 to $90 \mathrm{~min}$.

\section{Sample size}

About 20-25 patients (ideally a 70/30 male to female ratio) will be interviewed.

\section{Inclusion criteria}

Patients with history of ACS or known CAD who have undergone at least one or better yet multiple coronary procedures will be asked to participate. Patients must be able to communicate in German in order to understand the study information sheet, to provide informed consent and to answer questions of the interviewer.

\section{Exclusion criteria}

Patients with known anxiety disorders and those who do not match the inclusion criteria will be excluded.

\section{Recruitment and sampling}

The teaching physicians will ask patients who meet the study criteria as they come to the practice for routine care. Patients will be informed that participation is voluntary, that they can contribute to a better scientific understanding in the field and that non-participation has no adverse effect on their medical care. According to the patients' wishes, the practice will arrange an appointment for the interview, or the contact data will be passed on to the interviewer who will then contact the patient by phone. The recruitment will end after 20-25 interviews are conducted and saturation is reached.

\section{Interview guide}

We will use narrative, structured interviews as a survey method which is known for high methodological standards such as comparability, objectivity and transparency. ${ }^{24}{ }^{25}$ The interview guide (see table 1 ) was prepared by a multidisciplinary research team which includes a sociologist (AH) (qualified in qualitative research methods and interview techniques) and a Board-certified primary care physician and epidemiologist (BW). The interview guide was reviewed by an external Board-certified primary care physician specialised in psychotherapy and supervision. To familiarise herself with the field, the sociologist performed a participatory observation in a CC laboratory and interviewed cardiac patients in a general practice. The interview guide was based on these observations and conversations with patients as well as theoretical preparatory work from the field of qualitative research, our prior retrospective study and a systematic literature review.

\section{Compensation}

The participants will receive compensation in the form of a small gift worth $10 €$.

\section{Data analysis}

The interviews will be tape-recorded and transcribed according to a simplified transcription system ${ }^{26}$ by the research team prior to analysis. The transcripts will be anonymised so that no names or other identifying features will appear in any form of data reporting. Data will be analysed by means of qualitative content analysis according to Mayring using the summarising approach with a combination of inductive category development and deductive category application. ${ }^{27}$ Two researchers will work independently on a system of categories with a subsequent discussion of the systems until a consensus is reached. The interpretation will focus on emotional and factual arguments that motivate patients with stable CAD to undergo CC. In addition, the patients' needs and wishes will be analysed with regard to strategies for a future intervention. The following questions will guide our analysis:

1. What are reasons for stable patients to undergo CC?

2. How do patients deal with their heart disease (secondary prevention)?

3. Which processes do patients describe regarding decision-making for non-invasive and invasive coronary procedures?

4. What information needs exist on behalf of patients to better understand a stepwise diagnostic approach and thereby avoid low-appropriate CCs?

In order to compare different types of patients and how they deal with their heart disease, an empirical typification of patients will be conducted. ${ }^{28}$ Objectivity and reliability will be ensured by a second coder. Validity will be verified by construct validity, the verification of the results on the basis of proven theories and/or results from prior studies on plausibility. ${ }^{27}$

Qualitative data analysis will be performed using the software ATLAS.ti.

\section{Possible outcome of the analysis and benefits of the study}

We assume that patients have a high level of uncertainty and fears regarding an adverse outcome. From everyday experience in general practices, we also presume that there is a lack of confidence in non-invasive diagnostic procedures as well as a lack of detailed information about the disease and the effectiveness of secondary prevention (lifestyle changes, medication) as well as stepwise diagnostic algorithms. Our study is designed to provide the basis for interventions supporting the health literacy of patients with known $\mathrm{CAD}$ on the role of diagnostic algorithms. To meet this objective, we hypothesise that the confidence in guidelines will need to be strengthened and the understanding of pathological processes improved as well as uncertainties and fears addressed in order to minimise them. On the basis of the study results, we are planning to develop an intervention in the form of an educational video. This intervention will empower patients to improve shared decision-making together with their physicians. Overall, we aim to promote guideline adherence, reduce the number of inappropriate CC 


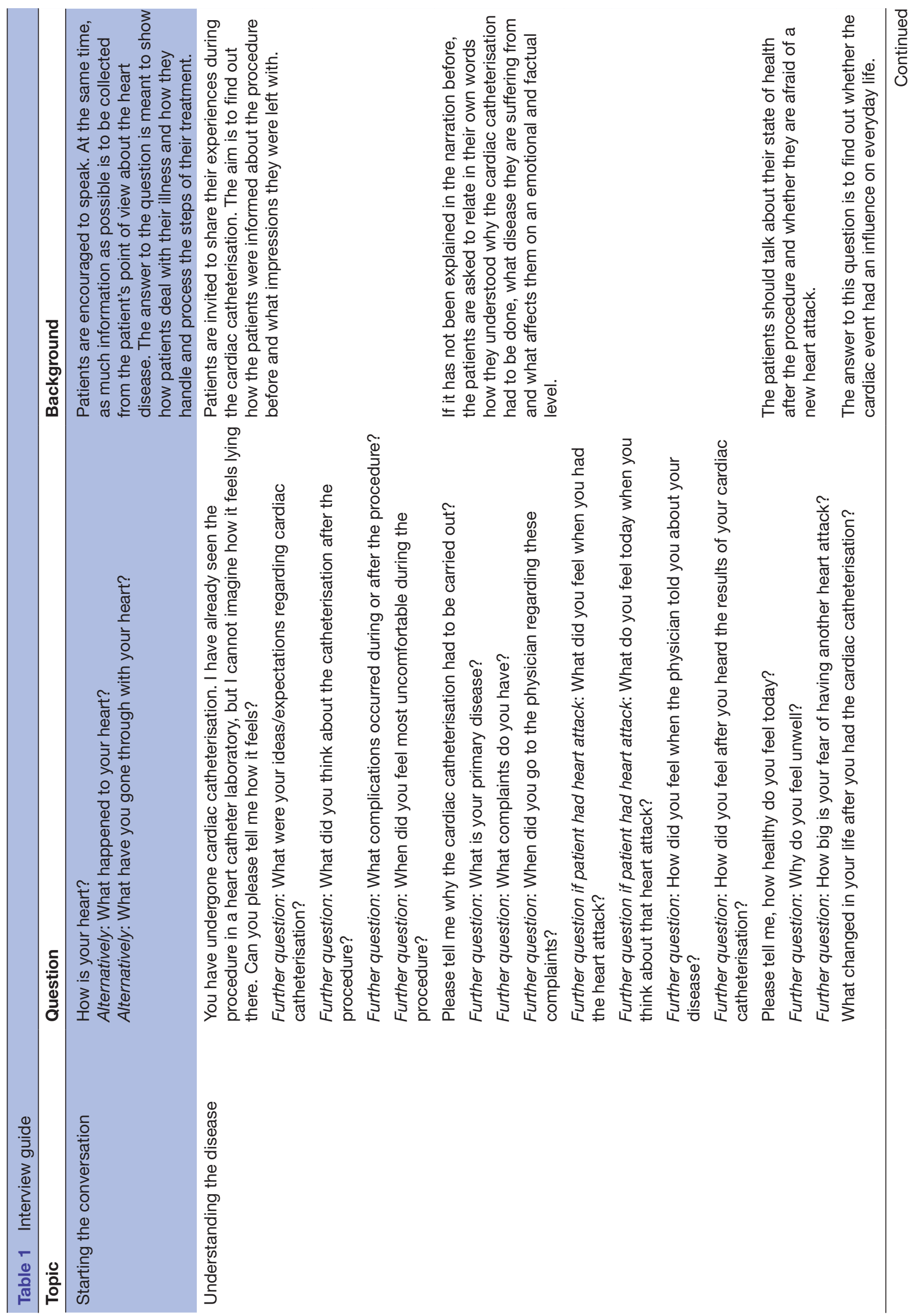




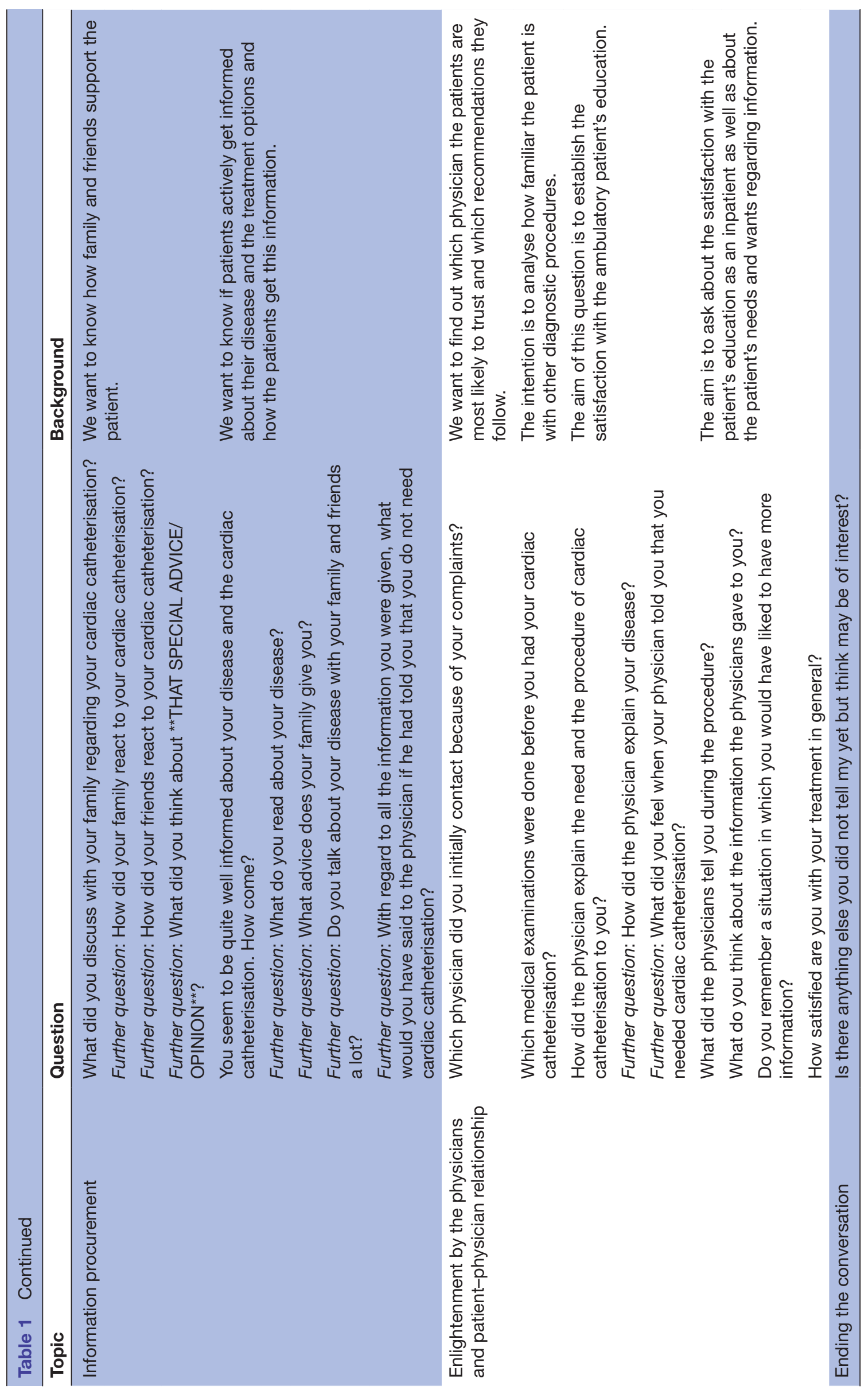


procedures and thereby decrease the risk of minor and major adverse effects including severe arrhythmias and death as well as radiation exposure.

\section{Ethics and dissemination}

All participants will receive an information sheet outlining the study, their voluntary participation and how their personal data will be protected. All participants will provide written informed consent. Procedures for pseudonymisation of the transcripts of the tape-recorded interviews will be outlined. Participants have the right to refuse answers to any question posed by the interviewer without disadvantages for the participants. The tapes will be erased on completion of the study. All electronic data will be stored in password-protected computers. Only the research team will have access to the data. Participants will not be identifiable in any publication or dissemination activity; confidentiality will be ensured by using study numbers to differentiate participant quotations. The findings will contribute to the development of an appropriate intervention. Results will be disseminated within the academic field (conference presentations, journal publications) and beyond. Our study report will adhere to the consolidated criteria for reporting qualitative studies.

Ethical approval for the study was obtained from the Ethics Committee of the Faculty of Medicine at the University of Duisburg-Essen, Germany (15-6448-BO).

Acknowledgements We would like to thank Ilka Aden for her helpful review of the interview guide.

Contributors AH: complemented the study concept, wrote the first draft of the manuscript. BW: developed the study idea and concept, revised the manuscript. Both authors critically reviewed the first draft and provided feedback on it. Both authors read and approved the final manuscript.

Competing interests None declared.

Ethics approval Ethics Committee of the Faculty of Medicine at the University of Duisburg-Essen, Germany (15-6448-B0)

Provenance and peer review Not commissioned; externally peer reviewed.

Open Access This is an Open Access article distributed in accordance with the Creative Commons Attribution Non Commercial (CC BY-NC 4.0) license, which permits others to distribute, remix, adapt, build upon this work non-commercially, and license their derivative works on different terms, provided the original work is properly cited and the use is non-commercial. See: http://creativecommons.org/ licenses/by-nc/4.0/

(c) Article author(s) (or their employer(s) unless otherwise stated in the text of the article) 2017. All rights reserved. No commercial use is permitted unless otherwise expressly granted.

\section{REFERENCES}

1. Gottwik M, Zeymer U, Schneider S, et al. Zu viele Herzkatheteruntersuchungen in Deutschland? DMW - Deutsche Medizinische Wochenschrift 2003;128:2121-4.

2. Scanlon PJ, Faxon DP, Audet AM, et al. ACC/AHA guidelines for coronary angiography: executive summary and recommendations. A report of the American College of Cardiology/American Heart Association Task Force on Practice Guidelines (Committee on Coronary Angiography) developed in collaboration with the Society for Cardiac Angiography and Interventions. Circulation 1999;99:2345-57.

3. Nichols M, Townsend N, Scarborough P, et al. European cardiovascular disease statistics. Brussels, Sophia Antipolis: European Heart Network; European Society of Cardiology, 2012.
4. Widimsky P, Wijns W, Fajadet J, et al. Reperfusion therapy for ST elevation acute myocardial infarction in Europe: description of the current situation in 30 countries. Eur Heart J 2010;31:943-57.

5. Boden WE, O'Rourke RA, Teo KK, et al. Optimal medical therapy with or without PCI for stable coronary disease. N Engl J Med Overseas Ed 2007;356:1503-16.

6. Weintraub WS, Spertus JA, Kolm P, et al. Effect of PCl on quality of life in patients with stable coronary disease. N Engl J Med Overseas Ed 2008;359:677-87.

7. Perk J, de BG, Gohlke H, et al. European guidelines on cardiovascular disease prevention in clinical practice (version 2012). The Fifth Joint Task Force of the European Society of Cardiology and Other Societies on Cardiovascular Disease Prevention in Clinical Practice (constituted by representatives of nine societies and by invited experts). Eur Heart J 2012;33:1635-701.

8. Bundesärztekammer (BÄK), Kassenärtliche Bundesvereinigung (KBV), Arbeitsgemeinschaft der Wissenschaftlichen Medizinischen Fachgesellschaften (AWMF), Kassenärztliche Bundesvereinigung (KBV). Nationale VersorgungsLeitlinie Chronische KHK Langfassung. 4. Auflage, Version 1: 2016.

9. Montalescot G, Sechtem U, Achenbach S, et al. ESC guidelines on the management of stable coronary artery disease: The Task Force on the Management of Stable Coronary Artery Disease of the European Society of Cardiology. Eur Heart $J$ 20132013;34:2949-3003;34:2949-3003.

10. Patel MR, Bailey SR, Bonow RO, et al. ACCF/SCAI/AATS/AHA/ ASE/ASNC/HFSA/HRS/SCCM/SCCT/SCMR/STS 2012 appropriate use criteria for diagnostic catheterization: a report of the American College of Cardiology Foundation Appropriate Use Criteria Task Force, Society for Cardiovascular Angiography and Interventions, American Association for Thoracic Surgery, American Heart Association, American Society of Echocardiography, American Society of Nuclear Cardiology, Heart Failure Society of America, Heart Rhythm Society, Society of Critical Care Medicine, Society of Cardiovascular Computed Tomography, Society for Cardiovascular Magnetic Resonance, and Society of Thoracic Surgeons. J Am Coll Cardiol 2012;59:1995-2027.

11. Chmiel C, Reich O, Signorell A, et al. Appropriateness of diagnostic coronary angiography as a measure of cardiac ischemia testing in non-emergency patients - a retrospective cross-sectional analysis. PLoS One 2015;10:e0117172.

12. Weltermann BM, Rock T, Brix G, et al. Multiple procedures and cumulative individual radiation exposure in interventional cardiology: a long-term retrospective study. Eur Radiol 2015;25:2567-74.

13. Achenbach S, Szardien S, Zeymer U, et al. Kommentar zu den Leitlinien der Europäischen Gesellschaft für Kardiologie (ESC) zur Diagnostik und Therapie des akuten Koronarsyndroms ohne persistierende ST-Streckenhebung. The cardiologist 2012;6:283-301.

14. Becker H-J. Früherkennung der koronaren Herzerkrankung ohne Katheter. Expertengespräch am 6. August 2002. 2002. http://www. herzstiftung.de/pdf/Expertengespraech.pdf().

15. Gray D, Hampton JR. Variations in the use of coronary angiography in three cities in the trent region. Heart 1994;71:474-8.

16. Stukel TA, Lucas FL, Wennberg DE. Long-term outcomes of regional variations in intensity of invasive vs medical management of medicare patients with acute myocardial infarction. JAMA 2005;293:1329-37.

17. Alter DA, Naylor CD, Austin PC, et al. Geography and service supply do not explain socioeconomic gradients in angiography use after acute myocardial infarction. CMAJ 2003;168:261-4.

18. Lin GA, Dudley RA, Redberg RF. Cardiologists' use of percutaneous coronary interventions for stable coronary artery disease. Arch Intern Med 2007;167:1604-9.

19. Goff SL, Mazor KM, Ting HH, et al. How cardiologists present the benefits of percutaneous coronary interventions to patients with stable angina. JAMA Intern Med 2014;174:1614-21.

20. Rothberg MB, et al. Patients' and cardiologists' perceptions of the benefits of percutaneous coronary intervention for stable coronary disease. Ann Intern Med 2010;153:307-13.

21. Fowler FJ, Gallagher PM, Bynum JPW, et al. Decision-making process reported by medicare patients who had coronary artery stenting or surgery for prostate cancer. J Gen Intern Med 2012;27:911-6.

22. Ockene IS, Shay MJ, Alpert JS, et al. Unexplained chest pain in patients with normal coronary arteriograms: a follow-up study of functional status. N Engl J Med 1980;303:1249-52.

23. Marstedt G, Buitkamp M, Braun B. Eine Patiententypologie: Befunde zur Differenzierung unterschiedlicher Normen und Verhaltensmuster von Patienten im Gesundheitssystem. In: Amhof R, Böcken J, Braun B, eds. Gesundheitsmonitor 2007: Gesundheitsversorgung und Gestaltungsoptionen aus der 
Perspektive von Bevölkerung und Ärzten. 1st edn. Gütersloh: Verl. Bertelsmann Stiftung, 2007:231-56.

24. Nohl A-M. Interview und dokumentarische Methode: Anleitungen für die Forschungspraxis. 4th edn. Wiesbaden: Imprint VS Verlag für Sozialwissenschaften, 2012.

25. Marotzki W. Leitfadeninterview. In: Bohnsack R, ed. Hauptbegriffe qualitativer Sozialforschung. 3rd edn. Opladen u.a: Budrich, 2011:114.
26. Dresing T, Pehl T. Praxisbuch Interview, Transkription \& Analyse: Anleitungen und Regelsysteme für qualitativ Forschende. 6th edn. Marburg: Dr. Dresing und Pehl GmbH, 2015.

27. Mayring P. Qualitative Inhaltsanalyse: Grundlagen und Techniken. 11th edn. Weinheim: Beltz, 2010.

28. Mayring P. Einführung in die qualitative Sozialforschung: Eine Anleitung zu qualitativem Denken. 6th edn. Weinheim und Basel: Beltz, 2016. 